\section{Implementação da política de saúde indígena no Pólo-base Angra dos Reis, Rio de Janeiro, Brasil: entraves e perspectivas}

\author{
Implementation of indigenous people's health \\ policy in Angra dos Reis, Rio de Janeiro, Brazil: \\ obstacles and prospects
}

Maria de Betania Garcia Chaves 1,2

Andrey Moreira Cardoso 2,3

Celia Almeida ${ }^{2}$

\footnotetext{
1 Unidade Municipal de Saúde Aldeia Indígena, Secretaria Municipal de Saúde de Angra dos Reis, Angra dos Reis, Brasil.

2 Escola Nacional de Saúde Pública Sergio Arouca

Fundação Oswaldo Cruz, Rio de Janeiro, Brasil.

3 Centro de Vigilância Epidemiológica, Secretaria de Estado de Saúde do Rio de Janeiro, Rio de Janeiro, Brasil.

Correspondência M. B. G. Chaves Departamento de Planejamento e Administração em Saúde, Escola Nacional de Saúde Pública Sergio Arouca, Fundação Oswaldo Cruz. Rua Leopoldo Bulhões 1480 Rio de Janeiro, $R J$ 21041-210, Brasil. betannia@terra.com.br
}

\section{Abstract}

This article discusses the Brazilian National Policy for Indigenous People's Health, formulated in the 1990s as part of the national Health Reform Movement and based on the creation (in 1999) of the Indigenous Healthcare Sub-System. Coordinated at the central government level under the administration of the National Health Foundation/Ministry of Health, the implementation of this sub-system required adaptations in the organization of health services systems at the local level, with the creation of Special Indigenous Health Districts. This configuration showed the need for dialogue and negotiation among the various institutions involved with indigenous affairs, from the perspective of overcoming various conflicts and operational difficulties. The current analysis identifies the difficulties in the implementation of a differentiated indigenous health policy under federal responsibility and within the decentralized Brazilian Unified Health System (SUS), since the absence of specific mechanisms and instruments regulating the operationalization of these services at the local level and the lack of more effective supervision and on-going evaluation of this policy mean that differentiated care for the indigenous population is subject to both the vices and virtues of local policy.

Health Policy; Health Planning; South American Indians

\section{Introdução}

A década de 80 significou um marco importante para o setor saúde no Brasil em decorrência das profundas transformações da política de saúde em âmbito nacional. Onze anos após o estabelecimento dos princípios do Sistema Único de Saúde (SUS) e da legitimação do direito dos povos indígenas à atenção à saúde de forma integral e diferenciada na Constituição Federal de 1988, e nove anos após a promulgação da Lei Orgânica da Saúde (1990) foi formulada a Política Nacional de Saúde Indígena, em 1999, operacionalizada com a Lei Arouca, do mesmo ano, que instituiu o Subsistema de Atenção à Saúde Indígena (SASI), sob gestão da Fundação Nacional de Saúde (FUNASA), do Ministério da Saúde (MS) 1.

Considerando a diversidade sócio-cultural, geográfica e política dos povos indígenas brasileiros e de suas diferentes formas de contato e graus de inserção no cotidiano da sociedade, bem como a heterogeneidade da implementação do SUS nas diferentes regiões, estados e municípios, cada contexto local ou regional tornase experiência singular no processo de implantação do novo Modelo de Atenção à Saúde Indígena.

Os Guaraní pertencem ao tronco lingüístico Tupi e se caracterizam por uma grande mobilidade espacial 2. Os Guaraní formam um grupo étnico diferenciado internamente e o seu 
deslocamento para o litoral do país, bem como para os Estados de São Paulo, Rio de Janeiro e Espírito Santo reconstituem historicamente sua migração ao longo destes últimos 170 anos. Constata-se que os primeiros grupos a se deslocar para o litoral vieram do Sul e do Estado do Mato Grosso, num período em que no Estado de São Paulo havia os remanescentes Tupi 3. O território Guaraní é descontínuo e carece de garantias, uma vez que várias áreas ocupadas por eles não são consideradas reservas indígenas. "A busca da 'Terra sem Mal' e de uma 'terra nova' estrutura marcantemente seu pensamento e suas vivências; a 'Terra sem Mal'é a síntese histórica e prática de uma economia vivida profeticamente e de uma profecia realista, com os pés no chão (...)" (Meliá, 1989, apud Rondinelli 3; p. 239).

A população Guaraní no Brasil é de aproximadamente 44 mil indivíduos distribuídos pelo Estado do Mato Grosso do Sul, litoral dos Estados do Espírito Santo, Rio de Janeiro, São Paulo, Paraná, Santa Catarina e Rio Grande do Sul, e há pequenos grupos espalhados pelos Estados de Tocantins e Maranhão. A população Guaraní que vive no sul fluminense, situada em Angra dos Reis e Parati, é estimada em 555 indígenas 4.

Os Guaraní residentes no Município de Angra dos Reis, totalizando 311 pessoas, ocupam uma área demarcada na aldeia de Sapukaí, na região do Bracuí, inserida no 4o Distrito Sanitário. Este trabalho apresenta uma primeira aproximação à questão da saúde indígena no Município de Angra dos Reis, no Rio de Janeiro, entre 1991/2001, portanto, período prévio e inicial da implantação do SASI, tendo como referência a dinâmica de formulação e implementação da Política Nacional de Saúde Indígena. A partir da análise da história da saúde indígena no Município de Angra dos Reis e de sua contribuição para a implantação dessa política nacional, levantam-se questões acerca de alguns problemas centrais para a consolidação desse modelo de atenção.

A principal conclusão é que, apesar dos avanços conseguidos na implementação do SUS, não são ainda levadas na devida consideração as especificidades da população indígena, mesmo tendo sido formulada uma política específica para ela, além de que a falta de coordenadas mais claras emanadas do nível federal dificultam ainda mais a implementação do SASI em nível local.

\section{A política de saúde indígena no Brasil}

A 8ạ Conferência Nacional de Saúde (8a CNS), realizada em 1986 e coordenada pelo Dr. Sergio Arouca, então presidente da Fundação Oswaldo Cruz (FIOCRUZ), foi um evento fundamental para a reformulação da Política Nacional de Saúde, ao aprovar as diretrizes básicas da reforma sanitária brasileira a ser implementada com o SUS. Essa conferência foi uma etapa importante de um processo de articulação nacional, promovido por atores os mais diversos, vinculados ao chamado Movimento pela Reforma Sanitária Brasileira, iniciado nos anos 70 e que formulou os princípios e diretrizes da reforma setorial no Brasil 5,6. Como parte desse movimento, constituiu-se, nos anos 80, o Movimento Sanitário Indigenista, também composto por profissionais de diferentes áreas, que militavam pelos direitos das populações indígenas, entre eles o direito à saúde 7 .

Essa dupla militância - sanitária e indigenista - possibilitou a inclusão da questão da saúde indígena na agenda de reforma, com a realização, concomitante a 8a $\mathrm{CNS}$, da 1a $\mathrm{Con}$ ferência Nacional de Proteção à Saúde dos Povos Indígenas. A 8a CNS referendou a recomendação, discutida e aprovada pela Subconferência sobre a saúde indígena, de que esta deveria ser coordenada pelo MS, por meio de um subsistema de serviços de saúde vinculado ao SUS. A 9a Conferência Nacional de Saúde (9a CNS), de 1992, resgatou tal recomendação ao aprovar o Modelo de Atenção à Saúde Indígena diferenciado e a indicação de realização da 2a Conferência Nacional de Saúde dos Povos Indígenas (CNSPI), que viria a acontecer em 19937.

Entretanto, a municipalização radical das ações de saúde, que foi a tônica das recomendações aprovadas na 9a CNS 6,8, foi discutida e questionada pelo Movimento Sanitário Indigenista, pois poderia colocar os povos indígenas à mercê das oscilações políticas locais. Isso levou à formulação de uma política específica para essas populações - a Política Nacional de Saúde Indígena -, com uma organização de serviços diferenciada (um subsistema), mas articulada ao SUS, organizada em distritos sanitários especiais, a chamada "Distritalização Diferenciada" 9, como solução para o dilema "descentralização sem municipalização". Essa estruturação foi pensada para "proteger" essas populações das diferentes capacidades de implementação em nível local. Para tal, a gestão dessa política deveria ser responsabilidade do nível central.

Essa proposta foi referendada pela 10a Conferência Nacional de Saúde (10ạ CNS), de 1996, 
que aprovou a regulamentação e implantação dos Distritos Sanitários Especiais Indígenas (DSEI) como unidades organizacionais do SASI, bem como indicou a realização da 3a Conferência Nacional de Saúde dos Povos Indígenas, que, entretanto, só foi realizada em 2003, dez anos depois da 2a CNSPI.

As recomendações da la Conferência Nacional de Proteção à Saúde dos Povos Indígenas contribuíram para a transferência, em 1991, da coordenação da saúde indígena da Fundação Nacional do Índio (FUNAI), do Ministério da Justiça, para a Fundação Serviços de Saúde Pública (FSESP), do MS (Decreto Presidencial n. 23/1991) 7. Nesse mesmo ano, foi criada, no MS, a Fundação Nacional de Saúde (FNS), a partir da fusão da FSESP e da Superintendência de Campanhas de Saúde Pública (SUCAM) 10, que passou a ser responsável por essa coordenação.

Nesse contexto, estabeleceu-se relação conflituosa entre a FNS e a FUNAI. Enquanto a FNS tentava administrar as dificuldades criadas pela fusão, a FUNAI enfrentava escassez de recursos financeiros e humanos. Em relação à questão indígena, enquanto a primeira possuía um corpo técnico preparado para trabalhar com as questões de saúde pública, não tinha a experiência que a segunda possuía para trabalhar com a complexidade da saúde indígena. Diante desses impasses, em 1994 a coordenação da política de saúde indígena retornou para a FUNAI (Decreto Presidencial n. 1.141/1994), que passou a liderar a recém-criada Comissão Intersetorial, que atribuiu à FNS a responsabilidade pelas ações de prevenção e controle de agravos à saúde, saneamento básico e capacitação de recursos humanos; e, à FUNAI, as ações de assistência médico-sanitária 1,7.

Paralelamente a esse processo de reorganização da condução da Política Nacional de Saúde Indígena, em meados da década de 90, o Movimento Sanitário Indigenista, com base nas diretrizes da 2ạ Conferência Nacional de Saúde para os Povos Indígenas, encaminhou ao Deputado Federal Sergio Arouca um documento solicitando a elaboração de projeto de lei para criação do Subsistema Diferenciado de Saúde Indígena, aprovado na Câmara dos Deputados cinco anos depois, constituindo-se na Lei Arouca (Lei n. 9.836/1999) 7.

Durante o período de tramitação desse projeto de lei, o conflito interinstitucional permaneceu e, em 1998, a Procuradoria Geral da República considerou inconstitucional a coordenação da saúde indígena pelo Ministério da Justiça/FUNAI. Os recursos materiais e humanos da FUNAI ligados à saúde indígena, assim como a gestão da Saúde Indígena, foram trans- feridos para a FNS (Medida Provisória n. 1.9118/1999 e Decreto Presidencial n. 3.156/1999, respectivamente) que, em 1999, adotou a sigla FUNASA. A partir desse momento, o SASI foi paulatinamente estruturado e organizado em 34 DSEI.

O conceito de DSEI foi definido como um espaço étnico-cultural dinâmico, geográfico, populacional e administrativo bem delimitado, que não guarda relação direta com os limites dos estados e municípios onde estão localizadas as terras indígenas. Visa a promover a reordenação da rede de saúde e das práticas sanitárias, e desenvolver atividades administrativo-gerenciais necessárias à prestação da assistência com controle social 1. Os DSEI devem prestar atenção básica à população indígena aldeada, mediante atuação de Equipes Multidisciplinares de Saúde Indígena (EMSI), nos moldes do Programa Saúde da Família (PSF), compostas por médicos, enfermeiros, odontólogos, auxiliares de enfermagem e Agentes Indígenas de Saúde. Esses serviços devem ser integrados e articulados à rede do SUS, de forma hierarquizada, tendo como instância regional os Pólos-base 1. As Casas de Saúde do Índio, sob responsabilidade da FUNASA, também integram a rede de referência do SASI, servindo para abrigar e cuidar dos pacientes e seus acompanhantes, durante períodos de tratamento em serviços de referência fora das aldeias 1 .

O financiamento desses distritos é majoritariamente público, composto por recursos orçamentários do MS/FUNASA e, complementarmente, pelos dos estados e municípios que têm populações indígenas, mas recebe também contribuições de organizações de cooperação mútua internacional e da iniciativa privada. A distribuição desses recursos é feita segundo critérios populacionais, perfil epidemiológico e características geográficas. As ações de atenção à saúde às populações indígenas podem ser executadas de forma direta, pelos municípios, ou indireta, por organizações não-governamentais 1 .

O controle social no SASI, em nível nacional, é viabilizado pela Comissão Intersetorial de Saúde Indígena, criada em 1991, pelo Conselho Nacional de Saúde, para assessorá-lo nessas questões. Essa comissão é composta por representantes da FUNAI, FUNASA, universidades e organizações indígenas e tem função consultiva. Em nível local esse controle é exercido pelos Conselhos Distritais e Locais de Saúde Indígena (Portaria MS 852/1999). Os Conselhos Distritais têm caráter deliberativo e composição paritária entre usuários, prestadores de serviços e trabalhadores de saúde, possuin- 
do como atribuições aprovar o plano distrital, avaliar a execução das ações de saúde e apreciar a prestação de contas dos órgãos executores. Os Conselhos Locais, de caráter consultivo, são compostos apenas por representantes indígenas nos Pólos-base, tendo como atribuições avaliar as ações e serviços de saúde, indicar conselheiros para outras instâncias de controle social e articular com os gestores locais para viabilizar a assistência à saúde 1 .

\section{A política de saúde indígena no Município de Angra dos Reis}

O Município de Angra dos Reis localiza-se no litoral sul do Rio de Janeiro. Sua autonomia política é recente, inclusive em relação às eleições diretas para escolha de seus dirigentes, por ter sido considerado área de segurança nacional até 1981. Em 1989, o segundo prefeito eleito (pertencente ao Partido dos Trabalhadores) teve entre as metas prioritárias de governo a legitimação da participação popular e a implantação do Sistema de Saúde Local, com a criação de cinco distritos sanitários, viabilizados com a assinatura do Convênio de Municipalização da Saúde, nesse mesmo ano (1989), na época vinculado ao Sistema Unificado Descentralizado de Saúde (SUDS). Esse convênio representou o alicerce para a estruturação do SUS no município, que se iniciou em 199011.

No final dos anos 80 e início dos 90, a lei orgânica do município contemplou questões relativas à população Guaraní residente no seu território 12 . O percurso para esse reconhecimento, entretanto, não foi linear nem isento de conflitos. Ao contrário, a luta dos Guaraní para ter direito a permanecer em suas terras e serem reconhecidos como cidadãos brasileiros é árdua e permanente, iniciando-se praticamente na segunda metade do século passado, mais especificamente, a partir dos anos 1970.

Em 1991, Angra dos Reis realizou sua primeira Conferência Municipal de Saúde (1ạ CMS), que teve como tema central a discussão dos princípios básicos do SUS, resultando na criação dos Conselhos Municipal, Distritais e Gestores de Saúde. A 1ạ CMS contou também com delegados indígenas e da FUNAI, apontou a necessidade de organização da assistência diferenciada à saúde dessa população, viabilizando a inserção de seus representantes nos conselhos participativos do sistema, inclusive no Conselho Gestor da Unidade Municipal de Saúde Bracuí, referência no SUS para os Guaraní, antecipando-se ao movimento nacional de responsabilização do MS pela saúde indígena.
As precárias condições de saúde dessa população, incluindo problemas advindos de seu contato com os grupos não indígenas, como o alcoolismo e aquisição de outros hábitos vetados na sua cultura, e as dificuldades para que os índios fossem atendidos nas unidades de saúde tradicionais, sobretudo pela discriminação, desconhecimento e desrespeito aos seus hábitos, tradições e modo de vida, levou os Guaraní a se organizarem, com o apoio dos não-índios simpáticos à sua causa, para reivindicar assistência à saúde na aldeia e mudanças significativas no modus operandi do sistema de saúde. Essa reivindicação foi levada ao Conselho Municipal de Saúde e, em 1992, um médico da unidade Bracuí passou a prestar atendimento semanal nessa área, sendo a dificuldade de acesso à aldeia contornada pela utilização de viatura e motorista cedidos pelo nível federal, responsável pelo monitoramento das endemias no município.

Face à exigência da Constituição Federal de 1988 de elaboração de Plano Diretor para cidades com mais de 20 mil habitantes, o governo municipal promoveu um fórum para discutir a responsabilidade social dos poderes públicos. O Plano Diretor, aprovado em 1992, incluiu o reconhecimento e a criação da Reserva Indígena Guaraní no Município de Angra dos Reis 12, que seria autodemarcada em 1993 e homologada em 1995 3. Com essas medidas, o governo de Angra dos Reis tornou-se um dos principais aliados do movimento Guaraní de luta pela terra.

Enquanto se observavam conflitos institucionais no âmbito federal, relativos à responsabilidade da gestão da saúde indígena, o município inaugurou, como resultado das reivindicações dos Guaraní, a primeira unidade municipal de saúde do país em área indígena (1995), conveniada com o SUS e em parceria com a FUNASA e FUNAI: a Unidade de Saúde da Aldeia.

Com base nas determinações referentes à Atenção à Saúde Indígena contidas na Norma Operacional Básica de 1996, houve um salto qualitativo nas ações básicas de saúde desenvolvidas nessa unidade. Nesse mesmo ano foi realizado concurso público para a Secretaria Municipal de Saúde (SMS), propiciando a contratação de profissionais para essa unidade, com cargas horárias definidas por critério populacional. Foram contratados médico clínico e pediatra, enfermeiro e auxiliar de enfermagem, além de psicólogo, dentista, zelador e motorista, selecionados em concurso anterior. Em 1998, o Agente Indígena de Saúde que já vinha trabalhando na aldeia, sem remuneração, foi contratado pelo Programa de Agentes Comunitários de Saúde (PACS) do município. Parte des- 
ses profissionais constituíram o que posteriormente seria a EMSI do SASI, que teve sua implantação favorecida pela minuta do Consórcio Intermunicipal de Saúde, organizado entre Angra dos Reis e Parati, em 1999. A partir de então, esses municípios compuseram o Pólobase Angra dos Reis, que integra o Distrito Sanitário Especial Indígena Litoral Sul.

Finalmente, a Câmara Municipal de Angra dos Reis reconheceu, em 1999, a inserção dos Guaraní na comunidade angrense 13 , contrapondo-se à tutela da FUNAI e configurando uma situação particular na história das conquistas dos Guaraní.

\section{O Pólo-base Angra dos Reis}

O Pólo-base Angra dos Reis é um dos 11 Pólosbase do DSEI Litoral Sul, que inclui o litoral dos Estados do Rio de Janeiro, São Paulo, Paraná, Santa Catarina e Rio Grande do Sul, e agrupa quatro aldeias com uma população de aproximadamente 555 indivíduos de etnia Guaraní. Sua sede, situada em Angra dos Reis, funciona como base administrativa para a EMSI. O Pólobase tem como sistema de referência e contrareferência as redes municipal e estadual de saúde. As Santas Casas de Misericórdia de Angra dos Reis e Parati, que já se constituíam como referências hospitalares para o atendimento indígena nos respectivos municípios, passaram a receber incentivo hospitalar para prestar esse atendimento ao subsistema indígena.

A EMSI, constituída por médico, dentista, enfermeiro, auxiliar de enfermagem e sete Agentes Indígenas de Saúde, passou a atuar com carga horária e remuneração diferenciadas, trabalhando em conjunto com profissionais da FUNASA (dois auxiliares de enfermagem originários da FUNAI, um motorista e um agente administrativo terceirizado) e aqueles lotados na Unidade de Saúde da Aldeia.

O histórico da política de saúde indígena local se configurou como uma perspectiva favorável à organização do Pólo-base, visto que o município havia estruturado uma rede física de atenção à saúde indígena, incluindo unidades de referência e contra-referência, e vinha construindo uma política de recursos humanos, com quadro de profissionais permanente, proveniente de concursos públicos, contrapondo-se à instabilidade advinda da terceirização em curso na saúde indígena em outras localidades. Ainda que a execução das ações seja desenvolvida pelos municípios (Angra dos Reis e Parati), é responsabilidade do governo federal a regulação do SASI (normatização, acompanha- mento e avaliação dos serviços prestados) $14 . \mathrm{O}$ não cumprimento dessa responsabilidade contribuiu, posteriormente, para maior exposição da organização pré-existente às variações e ingerências da política local, resultando, entre outras coisas, em problemas relacionados à articulação interinstitucional, aos recursos humanos e ao controle social.

\section{Articulações interinstitucionais}

Segundo a formulação original da Reforma Sanitária, as ações de saúde no SUS devem ser desenvolvidas de forma integrada e com a participação dos diferentes atores para que se atinja maior efetividade e impacto sobre a saúde de determinado grupo populacional. Esse conceito aplicado à gestão da saúde indígena se reveste de maior importância, na medida em que os povos indígenas apresentam especificidades culturais, são tutelados pela FUNAI, têm a gestão da saúde sob responsabilidade da FUNASA e vivem em estados e municípios que devem atuar de forma complementar na execução das ações de saúde. Em Angra dos Reis, a organização da atenção à saúde indígena cumpriu com esses pré-requisitos, sendo resultante da parceria, construída ao longo dos anos, entre a FUNAI, a FUNASA, a esfera municipal e a participação do movimento indígena.

Dois fatores podem ser considerados facilitadores, ou mesmo decisivos, para que o município se consolidasse como executor das ações no Pólo-base: já executar as ações de saúde indígena no espaço de seu território, em parceria com as instituições co-responsáveis; e estar habilitado na gestão plena do sistema municipal de saúde, desde 1996, possibilitando a transferência automática e direta de recursos do nível federal ao fundo municipal de saúde para pagamento da Equipe Multidisciplinar. Portanto, ao contrário do que Garnelo et al. 15 citam como um dos desafios para o funcionamento do subsistema do ponto de vista dos dirigentes da FUNASA, a baixa capacidade resolutiva, a morosidade e a insuficiência de estrutura das Secretarias Municipais de Saúde para execução das ações não se configuraram como dificuldades durante o período inicial de implantação do subsistema no Município de Angra dos Reis.

Entretanto, a implementação da Política Nacional de Saúde Indígena, a partir de 1999, deflagrou uma série de medidas, incluindo a publicação de portarias, a celebração de convênios ou assinatura de termos de adesão para a execução das ações de saúde. Apesar da elaboração de instrumentos de definição de repasse de recursos e de compromissos para execução 
dessas ações, se observou em Angra dos Reis o que se repetiu nacionalmente - a não definição clara dos papéis e responsabilidades das instituições envolvidas na prestação dos serviços. Da mesma forma, não houve definição por parte da FUNASA de mecanismos regulatórios para a aplicação dos recursos financeiros, acompanhamento e avaliação das ações a serem executadas. Isso contribuiu para uma maior autonomia da esfera municipal na condução desse processo, o que resultou em entraves subseqüentes em relação à utilização adequada dos recursos repassados e à execução satisfatória das ações de saúde, com reflexos deletérios nas relações interinstitucionais. Explicando melhor, a não definição de um processo de fiscalização sistemática pela FUNASA do uso dos recursos repassados pela Secretaria de Assistência à Saúde, do MS, para serem aplicados na saúde indígena levou à sua sub-utilização, com subseqüente estremecimento das relações entre as duas instituições.

Outro aspecto importante nas relações interinstitucionais ligado à organização do subsistema, se refere à coleta, fluxo e análise das informações. Como a Unidade de Saúde da Aldeia era, desde 1995, uma unidade cadastrada no SUS, a criação do Pólo-base não significou a eliminação da necessidade de registro e envio dos dados para os sistemas nacionais de informação. Por outro lado, a implantação do SASI deu origem ao Sistema de Informação de Saúde Indígena (SIASI), organizado na perspectiva da Vigilância em Saúde. Desde então, o fluxo de informações deveria ser pactuado pela FUNASA com os municípios e estados, a fim de garantir a alimentação contínua dos bancos de dados nacionais 1. No caso de Angra dos Reis, isso não aconteceu, acarretando multiplicidade de fluxos de informações e sobrecarga de trabalho para a EMSI, agravadas pela diversidade de formulários do SIASI, freqüentemente modificados.

Observou-se também a exigência, por parte do município, de execução no Pólo-base de algumas ações de programas verticais implementados pelo MS (por exemplo, pré-natal e prevenção de câncer de colo uterino) tal qual eram executadas nas outras unidades municipais de saúde, resultando em entraves para a adequação do modelo de atenção às especificidades culturais da população indígena, principal característica que se preconiza para o subsistema 15 , e evidenciando conflitos entre normatizações emanadas da instituição executora e as diretrizes da Política Nacional de Saúde Indígena.

Portanto, os diversos pontos de vista institucionais, graus de responsabilidade e níveis de interseção de esferas de atuação resultaram numa complexa relação entre os atores envolvidos na saúde indígena, bem ilustrada no texto de Garnelo et al. 15 (p. 52): “...não se evidenciam (...) estratégias de interação com os sistemas tradicionais de cura e cuidados e/ou com outras manifestações culturais dos grupos assistidos. Tampouco as formas de articulação com outros níveis do SUS, particularmente com os sistemas municipais de saúde, são claramente explicitadas - quer nos documentos oficiais da FUNASA, quer nos planos distritais -, obstaculizando o adequado fluxo de informações epidemiológicas e da movimentação de pacientes e gerando conflitos de atribuições entre gestores distritais e municipais de saúde". Essas limitações nas articulações interinstitucionais resultaram, no Pólo-base Angra dos Reis, na indefinição de fluxos político e administrativo, ocasionando pontos de tensão com repercussões na assistência à saúde prestada à população indígena.

\section{Recursos humanos}

Entre os critérios definidos pela FUNASA como necessários para a organização dos distritos sanitários encontram-se a disponibilidade, qualificação e perfil de recursos humanos para trabalhar com a saúde indígena. A Política Nacional de Saúde Indígena define que "a capacitação de recursos humanos para a saúde indígena deverá ser priorizada como instrumento fundamental de adequação das ações dos profissionais e serviços de saúde do SUS às especificidades da atenção à saúde dos povos indígenas e às novas realidades técnicas, legais, políticas e de organização de serviços" 1 (p. 15). Essas condições, vinculadas à alocação suficiente de pessoal qualificado para a execução de ações de saúde efetivas, são apontadas por Garnelo et al. 15 como um dos principais desafios para a implementação do subsistema.

Esse desafio já vinha sendo enfrentado pelo Pólo-base Angra dos Reis, pois os profissionais que integraram a EMSI haviam sido capacitados em aspectos antropológicos pelo Núcleo de Estudos em Saúde de Populações Indígenas da FIOCRUZ, anteriormente à implantação do subsistema, por já trabalharem na Unidade de Saúde da Aldeia. Outros profissionais ligados à atenção à saúde indígena nos municípios de Angra dos Reis e de Parati, incluindo os funcionários das unidades básicas de saúde e dos hospitais de referência desses municípios, também haviam recebido capacitação específica.

Uma vez que o Pólo-base de Angra dos Reis já contava com uma equipe estruturada, foi possível incluí-la também na capacitação de 
Instrutores/Supervisores no Módulo Introdutório de Saúde Indígena promovido pela FUNASA, ainda em dezembro de 1999. Porém, esses profissionais participaram apenas da parte teórica do módulo, não havendo continuidade da formação até 2001. Entretanto, a maioria dos técnicos do Pólo-base possuía capacitação na área de saúde pública, o que propiciou alguma adequação da organização de serviços de saúde no subsistema ao modelo proposto, contrapondo-se à experiência de outras regiões do país. Já para os profissionais de nível médio de enfermagem originários da FUNAI, a FUNASA não previu capacitação, mas eles foram inseridos nas atividades de formação promovidas pelo município.

A Política Nacional de Saúde Indígena explicita a importância do Programa de Formação de Agentes Indígenas de Saúde como ação estruturante dos Distritos Sanitários 1. Mas, como inicialmente não havia previsão de capacitação dos Agentes Indígenas de Saúde (AIS) do Pólo-base Angra dos Reis, estes foram capacitados junto com os agentes do PACS do município. Entretanto, devido à inadequação da metodologia, ao grau de instrução insuficiente dos agentes oriundos da população Guaraní e a divergências em relação às competências e responsabilidades dos AIS e dos agentes comunitários de saúde, essa capacitação não foi adequada às especificidades das populações indígenas. Ainda que, posteriormente, tenham ocorrido investimentos da FUNASA para a formação dos AIS no Pólo-base Angra dos Reis, os agentes de saneamento e de saúde bucal não foram incluídos nessa programação no período estudado.

Outra dificuldade significativa para a execução das ações de saúde nas aldeias, referida pelos autores, se refere à rotatividade de profissionais de saúde nos serviços, provocada não somente pela inadequação entre a formação profissional e as necessidades dos serviços, mas também pela ausência de mecanismos legais que garantam estabilidade nos contratos de trabalho, como ressaltado por Garnelo et al. 15, ao abordarem o tema dos recursos humanos vinculados à execução de ações de saúde pelas organizações não-governamentais. Esses problemas repercutem, em última análise, na impossibilidade de progressão na formação de competências técnicas, na ruptura dos vínculos entre profissionais e comunidades e na subutilização de investimentos em capacitação de recursos humanos. Vale ressaltar que esta problemática não se restringe à saúde indígena, configurando-se como uma questão mais geral, inserida nas discussões atuais sobre a im- plementação de uma política de recursos humanos mais condizente com as necessidades de atenção à saúde das populações e que propicie melhores condições de trabalho para os profissionais de saúde no Brasil 16.

Nessa perspectiva, um dos pontos favoráveis à execução das ações de saúde indígena no Município de Angra dos Reis no Pólo-base foi exatamente a forma de vínculo empregatício da maioria dos profissionais da EMSI, que eram concursados e contratados sob o regime estatutário, possibilitando continuidade das ações. Entretanto, como o profissional de enfermagem de nível superior e os AIS eram contratados sob o regime da Consolidação de Leis do Trabalho, e considerando esses vínculos como temporários, foram previstos mecanismos locais de recontratação desses profissionais com base em convênio específico entre a Prefeitura e o Conselho Municipal de Associações de Moradores, pagos com repasse de recursos do MS, a fim de prevenir entraves burocráticos para a manutenção desse quadro técnico.

Por outro lado, os profissionais de nível médio de enfermagem da FUNASA, por determinação federal, não puderam compor a EMSI, acarretando diversidade de vínculos empregatícios e discrepâncias salariais entre profissionais dessa categoria, gerando constrangimentos. Essas divergências e problemas gerados pelas distintas vinculações profissionais e diferentes níveis salariais também ocorreram entre a EMSI e as equipes do PSF.

Portanto, apesar da relativa estabilidade das equipes e das tentativas de minimização das implicações advindas da rotatividade de profissionais da EMSI observou-se, também em Angra dos Reis, dificuldades importantes no que concerne aos investimentos em capacitação técnica pela FUNASA e ao "mosaico" de situações de vínculos empregatícios, tornandose, com o passar dos anos, um desafio permanente a ser enfrentado pelo nível local.

\section{Controle social}

Conforme assinalam Garnelo et al. 15 (p. 80) “...o controle social em saúde indígena enfrenta singulares desafios para sua efetivação, tanto por razões ligadas às formas próprias do exercício do poder político no mundo indígena quanto pela dificuldade de apropriação pelos indígenas da lógica de funcionamento das instituições de saúde...".

Esses autores também apontam que a legitimidade da representação indígena é pautada nas relações de parentesco, e limitadas a elas, e que habitualmente se observa, em diversas culturas, que as representações nos espaços de 
controle social se concretizam com a participação daqueles indivíduos que possuem maior habilidade na comunicação com os não-índios, geralmente os mais novos; entretanto, o poder de decisão na estrutura social da aldeia encontra-se efetivamente na mão dos mais velhos, resultando que a participação dos mais novos nessas instâncias não os habilita a tomarem decisões nos processos de negociação.

No caso de Angra dos Reis, no período que antecede a implantação do SASI, os Guaraní já se faziam representar, desde 1991, em diversas instâncias de controle social, tais como nos Conselhos Municipais de Saúde e no Orçamento Participativo, nos Conselhos Gestores do Hospital Codrato de Vilhena e das Unidades Municipais de Saúde Bracuí e Aldeia, bem como nos fóruns do Conselho Municipal de Associações de Moradores e nas Conferências Municipais de Saúde realizadas até então 17.

A participação dos Guaraní nas instâncias referidas seguiu o modelo de representação por laços de parentesco. Entretanto, parece haver alguma diferença em relação ao que refere Garnelo et al. 15 , na medida em que a representação dos Guaraní ocorreu exatamente com a participação de indígenas mais velhos que conquistaram espaço de destaque nessas instâncias, contribuindo para suas conquistas. Os mais jovens, com maior domínio da língua portuguesa, acompanhavam as lideranças sem participar explicitamente das discussões.

A experiência do controle social acumulada pelos Guaraní nesses oito anos seria, a princípio, um facilitador para a participação indígena nas instâncias de controle social do subsistema. Contudo, a peculiaridade de já existir uma unidade do SUS na aldeia determinava a existência prévia de um Conselho Gestor dessa Unidade, paritário, que funcionaria como instância de controle social local, concomitante ao recém-criado Conselho Local de Saúde Indígena.

Dessa forma, o espaço de uma mesma aldeia comportava duas instâncias de controle social local, onde os representantes indígenas eram praticamente os mesmos, havendo confusão dos papéis a serem assumidos em cada um desses diferentes fóruns. As funções e atribuições desses dois conselhos não eram claras e, na prática, se sobrepunham. Apesar das reuniões indígenas para discussão de questões de interesse comunitário ligadas ao cotidiano constituírem-se em prática regular no espaço da aldeia, a convocação de reuniões pelo Conselho Local de Saúde Indígena para avaliar e acompanhar as ações de saúde mostrou-se incipiente no período de implantação do subsistema.
Concretamente, o controle social no Pólobase Angra dos Reis se resumiu, na fase inicial de implantação do subsistema, à participação dos indígenas em um único fórum - o Conselho Gestor da Unidade da Aldeia - a partir de convocação pelos não-indígenas. As atividades de controle social local no subsistema ficaram restritas à avaliação das ações e serviços de saúde oferecidos à comunidade nessa unidade. Mas, efetivamente, as questões da organização da atenção básica no Pólo-base não pareciam integrar o rol de preocupações da comunidade indígena no espaço de negociação dentro da aldeia, naquele momento, o que limitou de forma importante a sua participação nessa instância.

\section{Considerações finais}

Pensar uma política nacional de saúde para populações indígenas não é tarefa fácil. A especificidade desse povo exige que, para que possam ser atendidos no sistema de saúde, seja considerado seu "modo de vida" tradicional, isto é, sua cosmovisão e forma de organização social, política e cultural, o que pressupõe conhecer como pensam e vivem o processo saúde-doença, que na grande maioria das vezes difere completamente da percepção dos nãoíndios.

Obviamente, essa constatação coloca desafios formidáveis para a implantação do subsistema preconizado pela Política Nacional de Saúde Indígena.

São extremamente necessárias a organização da comunidade, indígena e não-indígena, além de decisão política e capacitação de profissionais, seja para se relacionarem de forma adequada com os índios, seja para reorganizar os serviços de saúde para poder atendê-los de forma efetiva.

Este trabalho indica que antes da promulgação da lei que institucionalizou essa política em nível nacional, o Município de Angra dos Reis já estabelecia relações com os indígenas e prestava algum tipo de atendimento de saúde, num primeiro momento de forma alternativa, mas, paulatinamente foi institucionalizando uma forma de atenção que, posteriormente, permitiu a implantação do SASI em nível local e possibilitou a criação do Pólo-base de Angra dos Reis.

Assim, no período 1991/2001, o município conseguiu formular e implementar uma política de saúde indígena cujos antecedentes foram prévios à dinâmica nacional, conduzida pelo nível federal, cumprindo com o compromisso 
de estar atento à população indígena residente no município, na Aldeia Sapukaí, no Bracuí. Anteriormente à implantação do SASI no município, como já havia uma equipe de funcionários públicos municipais trabalhando com os Guaraní, a relação entre os "dois mundos", o dos não-índios e o dos índios, foi administrada na área de saúde de forma quase satisfatória.

Entretanto, houve, e continua havendo, muita dificuldade para adequar o planejamento da Secretaria Municipal de Saúde, assim como de outros órgãos envolvidos com a questão indígena em níveis local e federal, à especificidade dessa população, devidas tanto à inexperiência dos técnicos locais, cuja rotatividade é inerente às mudanças políticas e institucionais no município, em termos gerais e na área de saúde em particular; quanto à persistente resistência dos índios às rotinas padronizadas pelos programas e ações de saúde oficiais, além dos problemas resultantes de sua inserção na sociedade.

Assim, quando da implantação do SASI em Angra dos Reis, em 1999, começaram a aparecer os entraves, conseqüentes, por um lado, à falta de definição de papéis claros das instituições responsáveis pela condução da saúde em área indígena, principalmente, em nível federal; e, por outro, a problemas referentes à própria implementação do SUS em nível local, subordinada a normas e determinações emanadas do nível central e que exigiram adequação da Secretaria Municipal de Saúde.

Ainda que essas exigências, emanadas do nível federal e vinculadas à descentralização SUS, tenham sido apropriadas de forma favorável aos índios no município, como por exemplo no período da adesão aos programas prioritários PACS e PSF, possibilitando a criação do Pólo-base de Angra dos Reis, essa dinâmica colocou novos problemas. A ausência de mecanismos e instrumentos específicos que regulamentassem de forma clara, seja o repasse de recursos financeiros, seja a organização dos serviços ou capacitação de recursos humanos, fez com que a atenção diferenciada aos povos indígenas estivesse submetida às vicissitudes ou virtudes da política local, como também às vontades particulares de cada dirigente setorial nesse nível de atenção.

A análise apresentada evidencia as dificuldades de implementação de uma política dessa natureza no âmbito do SUS. Apesar de instituída legalmente, a sua operacionalização é extremamente dificultada, pois ainda que o SUS esteja completamente descentralizado, a Política de Saúde Indígena segue coordenada pelo nível central, mas operacionalizada pelo nível local, por meio de parcerias interinstitucionais. Isso requer um esforço importante de adaptação e adequação em nível local, dependendo, em grande medida, das pessoas que ocupam os cargos de governo em momentos conjunturais específicos e, portanto, de sua habilidade de negociação e capacidade institucional de implementação.

No caso específico do Município de Angra dos Reis, historicamente houve um esforço importante de estruturação desse subsistema, mas que não escapou aos problemas mencionados acima.

Essa constatação remete à reflexão de que a estruturação do SASI deve necessariamente estar vinculada às diretrizes do SUS, conforme preconiza a Política Nacional de Saúde Indígena, que faz parte de uma história política e social sólida de construção da atenção à saúde pautada nas necessidades locais e especificidade dessas populações. Entretanto, deve ser construída no cotidiano da provisão de serviços em nível local, fazendo uso da experiência histórica acumulada e lidando com a realidade concreta em cada momento. Isso requer capacitação, monitoramento e avaliação permanentes, vale dizer, recursos específicos, materiais e humanos, além de suporte técnico adequado.

Sendo assim, numa política de responsabilidade da esfera federal, no SUS descentralizado, a atuação das instituições desse âmbito deveria ser pautada por regulação específica que estabelecesse não apenas as diretrizes de implementação, mas também proporcionasse apoio técnico para o desenvolvimento de capacidade de implementação em nível local, considerando-se a particularidade e diversidade de cada realidade. Isto pressupõe definição de fluxos de recursos (humanos, financeiros e materiais) e regras para sua utilização, além de mecanismos de supervisão e monitoramento de resultados, numa perspectiva de apoio à construção paulatina de autonomia para uma gestão descentralizada mais efetiva na área da Saúde Indígena.

Portanto, apesar dos avanços conseguidos em Angra dos Reis, esforços devem ser empreendidos em diversos âmbitos, tais como: (1) estabelecimento de uma política de recursos humanos que permita dirimir conflitos e garantir estabilidade do vínculo profissional, minimizando a rotatividade dos profissionais e potencializando a "atratividade" para o trabalho nessa área, além de preservar os resultados positivos já conseguidos; (2) definição de regulamentação específica que normatize o repasse de recursos financeiros, a sua utilização e ava- 
liação de resultados no âmbito mais amplo do processo de descentralização do SUS; e (3) definição clara de responsabilidades e mecanismos de sanção para o gestor local no que se refere à implementação da Política de Saúde Indígena, segundo as diretrizes definidas pelo nível central.

\section{Resumo}

Este artigo discute a Política Nacional de Saúde Indígena, formulada na década de 90 como parte da reforma sanitária brasileira, tendo como marco a criação, em 1999, do Subsistema de Atenção à Saúde Indígena. Coordenado pelo nível central, sob gestão da Fundação Nacional de Saúde/Ministério da Saúde, a implementação desse subsistema exigiu adaptações na organização dos sistemas de serviços de saúde em nível local, formulando-se os Distritos Sanitários Especiais Indígenas. Essa conformação evidenciou a necessidade de interlocução e negociação entre as diversas instituições vinculadas à questão indígena, na perspectiva de superar conflitos de múltipla natureza e dificuldades operacionais. A análise realizada neste trabalho aponta as dificuldades de implementação de uma política de saúde indígena diferenciada, sob a responsabilidade federal, no âmbito do SUS descentralizado, pois a ausência de mecanismos e instrumentos específicos que regulamentem a operacionalização desses serviços em nível local, assim como a falta de supervisão mais efetiva e avaliação permanente de resultados da implementação dessa política, fazem com que a atenção diferenciada à população indígena esteja submetida às vicissitudes ou virtudes da política local.

Política de Saúde; Planejamento em Saúde; Índios Sul-americanos
Para tal, seria necessária uma atuação coordenada de todas as instituições envolvidas com a questão indígena no Brasil, não apenas aquelas setoriais, na perspectiva de construção de uma "coalizão" política que possibilitasse maior força e apoio para a implementação dessa política nacional em nível local.

\section{Colaboradores}

Todos os autores participaram conjuntamente da elaboração do artigo. 


\section{Referências}

1. Fundação Nacional de Saúde. Política Nacional de Atenção à Saúde dos Povos Indígenas. Brasília: Departamento de Saúde Indígena, Fundação Nacional de Saúde, Ministério da Saúde; 2000.

2. Litaiff A. As divinas palavras: identidade étnica dos Guaraní-Mbyá. Florianópolis: Editora da UFSC; 1996.

3. Rondinelli RC. Inventário analítico do arquivo permanente do Museu do Índio - documentos textuais: 1950-1994. Rio de Janeiro: Museu do Índio; 1997.

4. Fundação Nacional de Saúde. Sistema de informação da atenção à saúde indígena: SIASI. Brasília: Departamento de Saúde Indígena, Fundação Nacional de Saúde, Ministério da Saúde; 2005.

5. Escorel S. Reviravolta na saúde: origem e articulação do Movimento Sanitário. Rio de Janeiro: Editora Fiocruz; 1998.

6. Pêgo RA, Almeida C. Teoría y práctica de las reformas de los sistemas de salud: los casos de Brasil y México. Cad Saúde Pública 2002; 18:971-89.

7. Verani CBL. A política de saúde do índio e a organização dos serviços no Brasil. Boletim do Museu Paraense Emílio Goeldi 1999; 15:171-92.

8. Müller Neto JS. Políticas de saúde no Brasil: a descentralização e seus atores. Saúde Debate 1991; (31):54-67.

9. Confalonieri UEC. A assistência médico-sanitária. In: Confalonieri UEC, Verani CBL, Marinho DP, Rigonatto DDL, organizadores. Saúde de populações indígenas: uma introdução para profissionais de saúde. Rio de Janeiro: Escola Nacional de Saúde Pública, Fundação Oswaldo Cruz; 1993. p. 1-39.

10. Senado Federal. Decreto presidencial n. 100. http:// www.senado.gov.br (acessado em 10/Jun/2003).
11. Secretaria Municipal de Saúde de Angra dos Reis. Relatório de gestão 1989-1992. Caderno de Saúde Volumes I e II. Angra dos Reis: Secretaria Municipal de Saúde de Angra dos Reis; 1992.

12. Guimarães G. Uma cidade para todos: o plano diretor do município de Angra dos Reis. Rio de Janeiro: Editora Forense; 1997.

13. Câmara Municipal de Angra dos Reis. Relatório da lei de diretriz orçamentária. Angra dos Reis: Câmara Municipal; 2000.

14. Garnelo L, Brandão LC. Avaliação preliminar no processo de distritalização sanitária indígena no Estado do Amazonas. In: Coimbra Jr. CEA, Santos RV, Escobar AL, organizadores. Epidemiologia e saúde dos povos indígenas no Brasil. Rio de Janeiro: Editora Fiocruz/ABRASCO; 2003. p. 235-57.

15. Garnelo L, Macedo G, Brandão LC. Os povos indígenas e a construção das políticas de saúde indígena no Brasil. Brasília: Organização Pan-Americana da Saúde; 2003.

16. Ministério da Saúde/Organização Pan-Americana da Saúde/Organização Mundial da Saúde/ Conselho Nacional de Secretários Municipais de Saúde. Relatório final do Seminário Política de Recursos Humanos para a Saúde: questões na área da gestão e regulação do trabalho. Brasília: Ministério da Saúde/Organização Pan-Americana da Saúde/Organização Mundial da Saúde/Conselho Nacional de Secretários Municipais de Saúde; 1999.

17. Secretaria Municipal de Saúde de Angra dos Reis. Relatório de gestão 2000. Angra dos Reis: Secretaria Municipal de Saúde de Angra dos Reis; 2000.

Recebido em 15/Dez/2004

Versão final reapresentada em 22/Ago/2005 Aprovado em 07/Nov/2005 